\title{
Epidemiology of sexual dysfunction in Asia compared to the rest of the world
}

\author{
Ronald W Lewis
}

There have been a limited number of epidemiological studies published on sexual disorders in persons from Asia. This paper aims to assess the reports of sexual dysfunction epidemiological studies published in the English language that involved Asian countries. Key points are summarized in this paper from nine epidemiological papers on sexual dysfunction from Asia that were published in the English language. Seven met the criteria for evidence-based studies reaching a Prins score of at least 10 or more. Papers included in this report came from national and regional representative studies in peer review journals. These results for sexual dysfunction in the nine papers are summarized for various sexual dysfunctions in men and women in Asian countries. In three of these, worldwide data were presented in the same paper allowing comparisons with Asian data on prevalence rates. Detailed descriptions from each of these studies are presented in paragraph form. More detailed data on erectile dysfunction (ED) is presented in a tabular form. Collectively, there seems to be a need for country- and population-specific further descriptive and analytical epidemiological studies in all of the sexual disorders from Asia. This critical review paper should help guide these studies for reaching evidence-based literature standards. Asian Journal of Andrology (2011) 13, 152-158; doi:10.1038/aja.2010.108; published online 15 November 2010

Keywords: descriptive epidemiology; male and female dysfunction; male ED; premature ejaculation

\section{INTRODUCTION}

Epidemiology of sexual dysfunction can be divided into descriptive and analytical epidemiology. Descriptive studies are results from community or special populations that deal primarily with prevalence and incidence data. Populations that produce either prevalence or incidence data can come from communities or clinics. Analytical epidemiology studies, on the other hand, deal with risk factors and the association of sexual dysfunction with these risks. Epidemiological data are the basis for assessing the impact of a condition on a given society. It is important that epidemiological studies are reasonably valid, in particular that they cover representative samples. There is a lot of heterogenicity in the literature which provides some stumbling blocks such as being often unable to disentangle true population affects from differences in reported prevalence that are simply due to inconsistent use of definitions and methods of collecting data.

In the age of evidence-based literature, ${ }^{1}$ it is recommended that some classification system such as that recommended by Prins and others, ${ }^{2}$ a classification system with a score of a maximum 15 points, would be required for being considered a valid epidemiological study. For inclusion in the report from the International Consensus Conference Committee in Paris, papers that have a score of 10 or more and have at least a $40 \%$ response rate were considered valid epidemiological studies. ${ }^{3,4}$ From that consensus conference seven papers cited included data from Asia regarding epidemiology of sexual function. This paper examines epidemiological data of sexual disorders from Asia published in the English literature in more detail. ${ }^{3}$

\section{METHODS}

The nine epidemiological papers from Asia to be presented in this paper were published in English and seven met the criteria for a Prins score of at least 10 and were included in the consensus committee book chapter. ${ }^{3}$ Papers included in this approach came from national and regional representative studies in peer review journals and chapters in books regarding epidemiological studies. The first paper discussed from China did not meet a score of 10 and one of the Asia studies was not included in the book chapter. It should have made the consensus conference for it meets a Prins score of 11.

The criteria for assessing methodological quality of prevalence studies consist of external and internal validity criteria producing a total of 15 points for validity. ${ }^{2}$ For external validity: the study period must be specified (providing one point); the source population must be random versus a study group that covers a complete population (for one point); eligibility criteria are age group that must be specified along with inclusion and exclusion standards (for two points); the characteristic of the group must be specified to describe the study population (providing one point); and finally, the response rate is greater than $70 \%$ or enough data are provided on non-responders to make inference on the representative nature of responders (providing one point). Therefore, there are six points available for external validity criteria.

For internal validity criteria, one point is awarded for prospective data collection; two points for the measurement instrument used in the study being validated and the period covered by it specified; another one point for the definition of the dysfunction stated; two

Section of Urology, Medical College of Georgia, Augusta, GA 30912, USA 
points for age- and gender-specific prevalence rates being used and possible dysfunctions are correlated; and finally, three points for informativity including the method of data collection described with question and answer possibilities stated and whether the prevalence rates are reproducible. Thus, for the internal validity criteria there are nine possible points.

\section{RESULTS}

In this paper, there are nine published Asian epidemiological studies on sexual function, six of which were from Asian countries only and three in which Asian data were included with world surveys in the same article. Table 1 summarizes the results for erectile dysfunction (ED) only in men who reached a Prins score of at least 10.

The first published Asian epidemiological study that met inclusion criteria at a Prins score of 10 was a sister study to the American study performed at the Mayo Clinic in Rochester (MN, USA). ${ }^{5}$ This was published in 1999 by Masumori and others in Urology. ${ }^{6}$ It was a community survey with a single asked question regarding sexual function in all men in a small fishing village surveyed with 289 responding producing a response rate of $46.8 \%$. Forty-two point three percent were analyzed. The age of participants was $40-79$ years with $61 \%$ being older than 60 years. The patients analyzed had no prostate or bladder cancer, neurogenic bladder, history of cerebral vascular accident or used antiandrogens. Erectile function was categorized in six different categories from all of the time being able to function to none of the time over the last month. For inclusion as ED in this study, only none or little of the time, two of the six categories defined entity. The prevalence rates for ED in this population were $15 \%$ for 40 - to 49 -year olds which numbered 47 patients; $23 \%$ for 50 - to 59 -year olds with a number of 65 participants; $39 \%$ for 60 - to 69 -year olds with a response of $107 \mathrm{men}$; and $71 \%$ for those 70-79 years old for a group of 70 men. Compared to the Mayo Clinic Olmstead County's study in which 2115

Table 1 Asian prevalence of ED

\begin{tabular}{|c|c|c|c|c|c|c|}
\hline $\begin{array}{l}\text { Author(s), year published } \\
\text { (Prins score) }\end{array}$ & Country of study & Population type & $\begin{array}{l}\text { Age of } \\
\text { participants } \\
\text { (years) }\end{array}$ & Eligibility criteria & $\begin{array}{l}\text { Number (\% } \\
\text { respondents) }\end{array}$ & $\begin{array}{l}\text { Differences/ } \\
\text { non-responders }\end{array}$ \\
\hline $\begin{array}{l}\text { Masumori et al., } 1999^{6} \\
\text { (10) }\end{array}$ & Japan & $\begin{array}{l}\text { All men in a } \\
\text { fishing village }\end{array}$ & $40-79$ & $\begin{array}{l}\text { No prostate or bladder } \\
\text { cancer or surgery, } \\
\text { antiandrogen, CVA or } \\
\text { neurogenic bladder }\end{array}$ & $\begin{array}{l}289(46.8 \%) ; 42.3 \% \\
\quad \text { analyzed }\end{array}$ & NS \\
\hline Kongkanand, $2000^{7}(11)$ & Thailand & $\begin{array}{l}\text { Region stratified } \\
\text { RPS }\end{array}$ & $40-70$ & NS & 1250 & NS \\
\hline $\begin{array}{l}\text { Nicolosi et al., } 2004^{13} \\
\text { (11) }\end{array}$ & $\begin{array}{l}\text { Northern Europe: Austria/ } \\
\text { Belgium/Germany/Sweden/ } \\
\text { United Kingdom } \\
\text { Southern Europe: Italy/France/ } \\
\text { Israel/Spain } \\
\text { Non-European West: Australia/ } \\
\text { Canada/ New Zealand/South } \\
\text { Africa/United States } \\
\text { Central/South American: Brazil/ } \\
\text { Mexico } \\
\text { Middle East: Algeria/Egypt/ } \\
\text { Morocco/Turkey } \\
\text { East Asia: China/Hong Kong } \\
\text { (China)/Japan/Korea/Taiwan } \\
\text { Southeast Asia: Malaysia/ } \\
\text { Philippines/Singapore/ } \\
\text { Thailand }\end{array}$ & RPS & $40-80$ & $\begin{array}{l}\text { Men and women } \\
\text { householder }\end{array}$ & $\begin{array}{l}27500(19 \%) ; 13618 \\
\text { men }\end{array}$ & \\
\hline $\begin{array}{l}\text { Nicolosi et al., 2001- } \\
2002 / 2005^{9}(11)\end{array}$ & $\begin{array}{l}\text { Mainland China, Hong Kong } \\
\text { (China), Taiwan, South Korea, } \\
\text { Japan, Thailand, Malaysia, } \\
\text { Indonesia, Singapore, } \\
\text { Philippines }\end{array}$ & RPS & $40-80$ & $\begin{array}{l}\text { Men/women urban } \\
\text { residents }\end{array}$ & $\begin{array}{l}6700(27 \%) ; 3350 \\
\text { men }\end{array}$ & NS \\
\hline $\begin{array}{l}\text { Laumann et al., 2001- } \\
2002 / 2005^{14}(14)\end{array}$ & World & RPS & $40-80$ & $40-80$ years & $13750(19 \%)$ & NS \\
\hline
\end{tabular}


Table 1 (Continued) Asian prevalence of ED

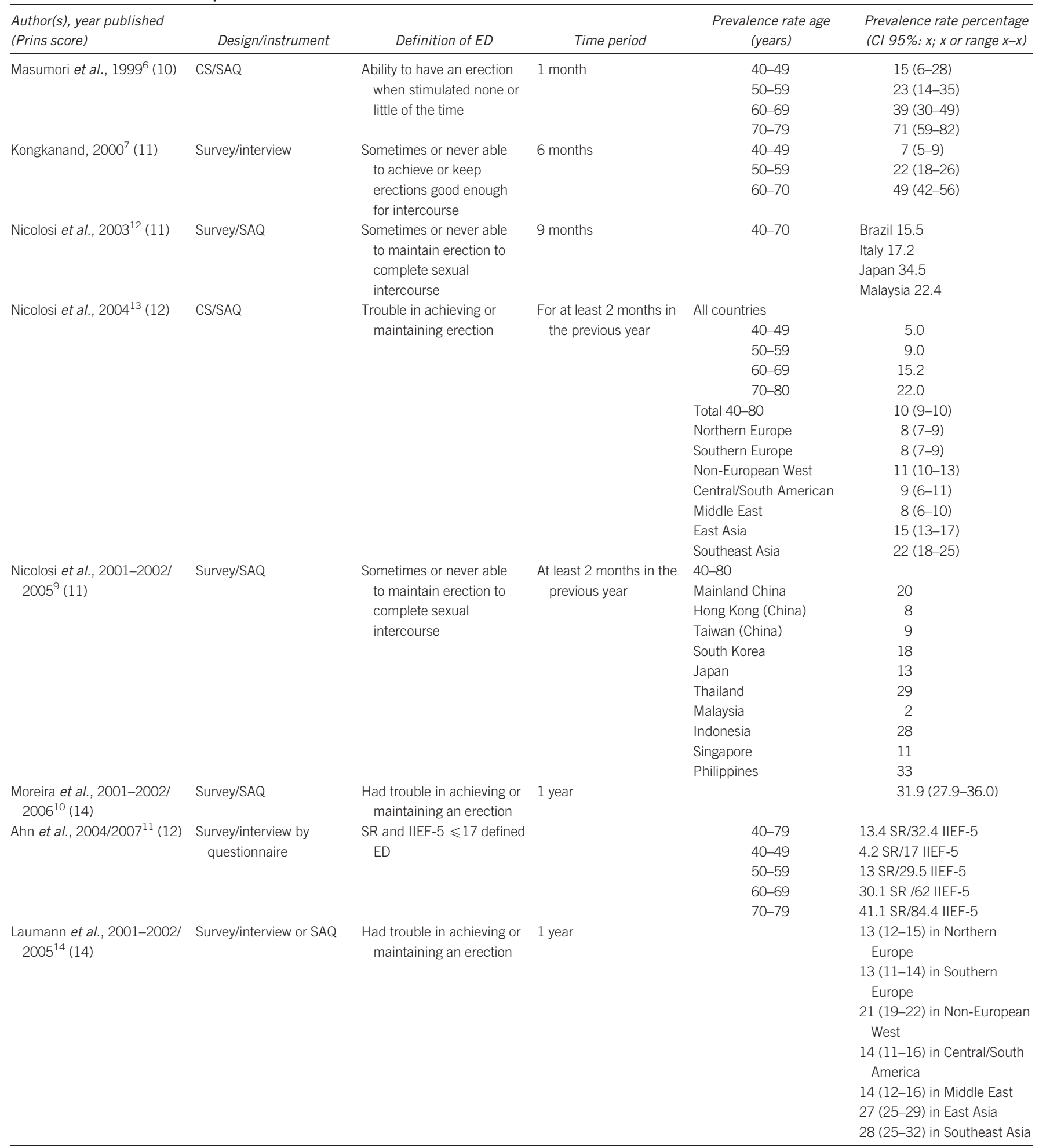

Abbreviations: CI, confidence interval; CS, community survey; CVA, cerebral vascular accident; ED, erectile dysfunction; IIEF, International Index of Erectile Function; NS, not stated; RPS, random population sample; SAQ, single asked question; SR, self-reported.

men participated, a 55\% respondent rate, the following values were found: for 40 - to 49 -year olds there was only $1 \%$ of ED in the 788 men responding (compared to $15 \%$ of Japanese men); ED prevalence rate was $6 \%$ in a group of 597 men responding (versus $23 \%$ for the Japanese study) for patients 50-59 years of age; or those 60-69 years of age, $22 \%$ of the Olmstead County group in a reported number of 418 (which were $39 \%$ to the Japanese study); and finally, in the most elderly group of 70 - to 79 -year olds $44 \%$ of 234 reporting (would compare to $71 \%$ in the Japanese similarly aged men). ED and decreased sexual libido were more frequently reported by Japanese 
men compared to Americans, but worry and concerns showed no striking differences between the studies. Differences between the two cultures in perception of aging or adaptation of lifestyles with aging and differences in perception of sexual function are important as well as differences in willingness to report sexual problems. These differences may partially explain the results of the different prevalence rates between the two societies. Similarly, differences in medication, diet, alcohol consumption and lifestyle habits were not controlled between the two population studies.

The second publication of an epidemiological study from Asia that appeared in the literature which met a Prins score of 11 was from Thailand and was published by Kogkanand and his associates in the year $2000 .^{7}$ This was a region-stratified regional population study of 1250 men aged $40-70$ years. They were surveyed interview style with ED defined as being sometimes or never able to achieve or keep erection good enough for intercourse over the previous 6 months. The prevalence rates were $7 \%$ for those $40-49$ years of age, $22 \%$ for $50-59$ years of age, $49 \%$ for $60-70$ years of age and $37.5 \%$ for the entire group of 40 - to 70 -year olds.

The third Asian study in the English literature was from China. It was the first population-based study from China that was reported by Lau and others in 2005. ${ }^{8}$ It was based upon data obtained from Dengfeng County of the Hunan Province which was a $90 \%$ rural population. This study, however, did not meet a Prins score of at least 10. Previous published studies from China were not population-based studies. This was a younger group of men 20-45 years of age and they were all married with a return of 298 of 380 questionnaires (78\%). This was a random selection of 10 villages of 5 of 17 randomly selected districts from a random sample of 1198 wives. Thus, selection as a man for the interview came directly from a previous survey of the wives. The question that was asked for ED was the following: have you experienced erectile problems while you were having sex in the past 12 months? Smoking and the wife having a sexual dysfunction were more likely predictors for husbands to have sexual dysfunction. Educational level, age at marriage and level of alcohol consumption were not factors that played a role in ED. Sharing a bedroom with another non-spouse was a predictor of sexual dysfunction in the husbands. The prevalence rates for ED were $18.9 \%$ in 20 - to 29 -year olds $(n=122), 10.4 \%$ in 30 - to 39 -year olds $(n=164)$ and $16.7 \%$ in 40 - to 45 -years olds $(n=12)$. The prevalence rates for premature ejaculation were $21.3 \%$ in 20 - to 29 -year olds $(n=122), 17.7 \%$ in 30 - to 39 -year olds $(n=164)$ and $25 \%$ in 40 - to 45 -year olds $(n=12)$. Other sexual disorders studied in the men included lack of drive for sex, inability to achieve ejaculation, anxiety about sexual performance, physical pain during intercourse and not finding sex pleasurable. Of the 298 respondents, $28.8 \%$ reported at least one sexual dysfunction and $24.5 \%$ reported having two or more. This rate of $28.8 \%$ was a lower prevalence for sexual dysfunction than reported by a sample of married women from the same area (43.4\%).

The fourth published epidemiological study in the English literature from Asia was published by Nicolosi and others in 2005. ${ }^{9}$ This paper was not included in the Paris consensus data chapter, but other similar papers were and all of those received a Prins score of at least 11. It was a random population sample carried out in the year 2001-2002 among urban residents aged 40-80 years in Mainland China and Hong Kong (China), Taiwan, South Korea, Japan, Thailand, Malaysia, Indonesia, Singapore and the Philippines. This was part of the Global Study of Sexual Attitudes and Behaviors (GSSAB). Intercept method interviews based on standardized questionnaires were used in all countries except Japan where questionnaires were mailed to samples of population derived from national telephone directories. The questionnaires were complete by 6700 people, 3350 each in men and women with a $27 \%$ response rate. They were questioned about occurrence for at least 2 months in the previous year for occasional, sometimes and frequently reported sexual dysfunction. More than $20 \%$ of men and $30 \%$ of women reported at least one sexual dysfunction. Early ejaculation $(20 \%)$ and $\mathrm{ED}(15 \%)$ were the most frequent problems in men, and lack of sexual interest (27\%), lubrication difficulty (24\%) and inability to reach orgasm $(23 \%)$ were the most frequent problems for women. The highest rate of sexual activity was in men from Mainland China (98\%) and from South Korea and Thailand (90\%). The lowest rate of sexual activity was in women from Thailand which was only $44 \%$. A sample size was 500 men and women in all of the 10 Asian nations except South Korea where the sample size were 1200 and in Japan where it was 1500. Early ejaculation varied from 9 to 45\% (in data obtained from the Philippines) with the lowest incidence in Indonesia of $9 \%$ and Hong Kong (China) of 10\%. Early ejaculation was reported in $22 \%$ of the population from China. Erection difficulties range $2-33 \%$ with the lowest in Singapore and the highest in the Philippines. The rate of erection difficulties in China was 20\%. Lack of interest in sex by women ranged from $17 \%$ in South Korea to $42 \%$ in Malaysia. In China, the rate of lack of interest in sex by women was $21 \%$. Inability to achieve orgasm in women ranged from $4 \%$ in Singapore to $56 \%$ in the Philippines. China reported a rate of $25 \%$. Lubrication difficulties ranged from a low of $14 \%$ in Indonesia and Singapore to a high of $50 \%$ in the Philippines. China reported a rate of $25 \%$. At least one dysfunction in men was present in men from $22 \%$ in Singapore to $65 \%$ in the Philippines. This rate of at least one dysfunction in men was 37\% in China. At least one dysfunction in women was present from $32 \%$ in Singapore to $82 \%$ in the Philippines. This rate in China was $45 \%$.

The fifth published Asian epidemiological study in the English literature was reported in 2006 by Moreira and associates and was assigned a Prins score of $14 .^{10}$ This was a random population study of six hundred 40 - to 80 -year-old Korean males with a $32.5 \%$ response rate. Again these are data extracted from the GSSAB study. This was a single asked question of a survey type using intercept methodology in which ED was defined as having trouble in achieving or maintaining an erection for 2 months or more during the previous year. In this paper prevalence rates were compared to data previously published in the East Asian region (China (including Hong Kong), Japan and Taiwan) and Southeast Asia region (Indonesia, Malaysia, Philippines, Singapore and Thailand). The prevalence rate of ED in Koreans was $15.1 \%$ versus $13.8 \%$ in East Asia and $17.5 \%$ in Southeast Asia. For frequent $\mathrm{ED}$ (with the other categories being occasional or periodic) the respective values were $3 \%$ versus $4.5 \%$ versus $4.3 \%$. The prevalence rate for premature ejaculation in Koreans was $20.8 \%$ versus $19.4 \%$ in East Asia versus $21.2 \%$ in Southeast Asia. For frequent premature ejaculation the rates were $3.1 \%$ versus $6.8 \%$ versus $3.7 \%$. Using the ages $40-49$ years as a reference age, the odds ratio was 2.17 for 50 - to 59 -year-old Koreans and $2.25 \%$ for 60 - to 80 -year-old Koreans presenting with ED compared to the 40-49 decade. Smoking was significantly associated with the higher odds ratio for ED and premature ejaculation. In this particular study, very few patients had been asked by a doctor about possible sexual dysfunction (5\%) during a routine office visit during the last 3 years despite $35 \%$ of men thinking that a doctor should ask patients about their sexual function. The prevalence rate of lack of pleasure from sex in women was $21 \%$ for Koreans versus 21.2\% for East Asia versus 22.9\% for Southeast Asia. The prevalence for inability to reach orgasm in women was $15 \%$ for Koreans versus 
25.7\% for East Asians versus 29.5\% for Southeast Asian. The prevalence for lubrication difficulties in the females in this study was $17.2 \%$ for Koreans versus 26.7\% for East Asian countries versus 25.8\% for Southeastern Asian countries. Aging in the women's dysfunction only correlated with lack of sexual interest.

A second study from Korea (the sixth from Asia) in the English literature was published in 2007 by Ahn et al. ${ }^{11}$ reaching a Prins score of 12 . This was a region-stratified random population study of 1570 men from 40 to 79 years of age and is similar to a population published in the National Health and Nutrition Survey from that country. The study was a survey/interview by questions comparing self-reported presence of disorder versus the International Index of Erectile Function-5 (IIEF-5) survey with scores of less than or equal to 17 defining ED. The prevalence rate for ED was $13.4 \%$ from self-reporting for the entire group for ED compared to $32.4 \%$ by using a more strict criterion as defined by the IIEF-5 survey. When broken up into age groups, the following was seen: $4.2 \%$ for self-reported versus $17 \%$ using the IIEF-5 for 40 - to 49 -year olds; $13 \%$ using self-reporting versus $29.5 \%$ using the IIEF- 5 for 50 - to 59 -year olds; $30 \%$ for self-reporting versus $62 \%$ using the IIEF- 5 for 60 - to 69 -year olds and $41 \%$ for selfreporting versus $84.4 \%$ using IIEF-5 for 70 - to 79 -year olds. The prevalence rates for premature ejaculations were $11 \%$ for 2-min cut-off time and $33.1 \%$ for 5 -min cut-off time.

There are three papers in which Asian data were included with data from other countries. The first was published in 2003 by Nicolosi and others reaching a Prins score of $11 .^{12}$ This was a random population sample with data from survey single asked questions collected by telephone in Italy, interviews in person in Brazil, by telephone and/or in person in Malaysia, and self-administered questionnaires in Japan. The response rate varied greatly for the four regions: $92 \%$ in Brazil, $72 \%$ in Italy, $51 \%$ in Japan and only $16 \%$ in Malaysia. This was a random population sample of 40 - to 70 -year-old householders using a single question that defined ED as being sometimes or never able to maintain an erection to complete sexual intercourse. The prevalence rate for ED in Brazil was 15\%, Italy 17.2\%, Japan 34.5\% and Malaysia $22.4 \%$. The age pattern and association with background diseases and behavior are similar among all of the studies. Differences in the ED rates were suggested by the authors as possibly reflecting cultural differences and the perception of attitudes toward and willingness to report ED.

The second published worldwide epidemiological study in the English literature that included Asian countries was published in 2004 by Nicolossi and others with a Prins score of $11 .^{13}$ It was a random population sample of 40 - to 80 -year olds in 29 countries, with data collected mostly by telephone interviews with a mix of telephone and in-person interviews in Mexico and door-to-door interviews in the Middle East and South Africa. Intercept methods were used in Asia except in Japan where questionnaires were sent to random selected people from a national telephone database. There was not a true sample of the entire population. ED was defined as having trouble in achieving or maintaining an erection for a period of 2 months or more during the previous year. Early ejaculation was self-reported from this survey. This was divided into seven regions of the world: Northern Europe, Southern Europe, non-European West, Central and South America, Middle East, East Asia (Mainland China, Hong Kong (China), Japan, Korea and Taiwan) and Southeast Asia (Malaysia, Philippines, Singapore and Thailand). The Indian subcontinent was not represented. Data were presented from 13618 men and 13883 women aged $40-80$ years which represented $19 \%$ of the sample group. Premature ejaculation was the most commonly reported sexual dysfunction in men and lack of sexual interest was the most common sexual dysfunction in women. The prevalence rates in early ejaculation for the entire study were $13 \%$ for 40 - to 49 -year olds, $14 \%$ for 50 - to 59 -year olds, $17 \%$ for 60 - to 69 -year olds, $18 \%$ for 70 - to 80 -year olds and $15 \%$ for the entire group of 40 - to 80 -year olds. For the different regions, early ejaculation was reported in the following percentages: $10 \%$ in Northern Europe, $13 \%$ in Southern Europe, $16 \%$ in non-European West, $22 \%$ in Central/South America, $8 \%$ in the Middle East, 19\% in East Asia, 25\% in Southeast Asia and 14\% for the entire study. The prevalence rates of ED for the entire study were $5 \%$ for 40 - to 49 -year olds, $9 \%$ for 50 - to 59 -year olds, $15 \%$ for 60 - to 69 -year olds, $22 \%$ for 70 - to 80 -year olds, and $10 \%$ for 40 - to 80 -year olds. The prevalence rates of ED for the different regions were as follows: $8 \%$ in Northern Europe, $8 \%$ in Southern Europe, $11 \%$ in non-European West, 9\% in Central/South America, $8 \%$ in the Middle East, 15\% in East Asia, 22\% in Southeast Asia and 10\% for the entire study. The prevalence rates of lack of interest in sex for women in the entire study were $18.5 \%$ for 40 - to 49 -year olds, $23 \%$ for 50 - to 59 -year olds, $24 \%$ for 60 - to 60 -year olds, $25.5 \%$ for 70 - to 80 -year olds and $21 \%$ for 40 - to 80 -year olds. The prevalence rates of lack of interest in sex by women from the different regions were as follows: 17\% for Northern Europe, 21\% for Southern Europe, 19\% for non-European West, 20\% for Central/South America, 29\% for the Middle East, 27\% for East Asia, 34\% for Southeast Asia and 21\% for the entire study. The prevalence rates of the inability to achieve orgasm in women for the entire study were $14 \%$ in 40 - to 49 -year olds, $18 \%$ in 50 - to 59 -year olds, $19 \%$ in 60 - to 69 -year olds, $20 \%$ in 70 - to 80 -year olds, and $16 \%$ in the entire group of 40 - to 80 -year olds. The prevalence rates of the inability to reach orgasm for women in the different regions were 10\% for Northern Europe, 17\% for Southern Europe, $16 \%$ for non-European West, 16\% for Central/South America, 17\% for the Middle East, 23\% for East Asia, 34\% for Southeast Asia and $16 \%$ for the entire study. The prevalence rates for lubrication difficulties for women in the entire study were $12 \%$ for 40 - to 49 -year olds, $19.5 \%$ for 50 - to 59 -year olds, $23 \%$ for 60 - to 69 -year olds, $21 \%$ for 70 to 80 -year olds and $16 \%$ for the entire group of 40 - to 80 -year olds. The prevalence rates for lubrication problems in women for the different regions were as follows: $13 \%$ from Northern Europe, $12 \%$ from Southern Europe, 19\% from non-European West, 18\% in Central/ South America, 12\% for the Middle East, 28\% for East Asia, 28\% for Southeast Asia and 16\% for the entire study.

The third worldwide epidemiological study in which Asian countries were included was from Laumann and others published in 2005, reaching a Prins score of almost perfect of $14 .{ }^{14}$ It was a more detailed report of the GSSAB than previous studies. Again, intercept and doorto-door methods of data collection were used, which is more reflective of urban populations. This type of intercept and door-to-door methods were used in East Asia, Southeast Asia, South Africa and Middle Eastern countries. This was restricted to analysis of data to those 11 205 respondents who had intercourse at least once in the past year and this tended to drop older respondents. Respondents reported on how often they thought about sex which became a proxy for sexual libido and whether they agreed with the belief that aging reduced sexual desire and/or behavior. Countries with covariance patterns that were significantly different from pooled samples were dropped from the analysis. Because of this, data regarding orgasm problems from Taiwan, Indonesia, Philippines and Singapore were eliminated. For lubrication problems, data from Taiwan and the Philippines were eliminated. For early ejaculation data from Korea, Malaysia, Philippines and Singapore were dropped from the sample, and for 
erectile difficulties data from Korea, Malaysia and Thailand were not included in the study in the pooled data. In most cases, the prevalence of sexual problems was higher in East Asia and Southeast Asia. For women the lack of interest in sex and the inability to reach orgasm were the most common sexual problems across the world ranging 26$43 \%$ and $18-41 \%$ respectively. For men, early ejaculation was the most reported problem with this reaching 31\% in men in Southeast Asia. Lubrication problems in women and erectile problems in men were relatively common and showed similar prevalences across most regions. Those exceptions were East Asia and Southeast Asia where the prevalence for both complaints was approximately doubled that reported in other regions. Older age consistently increased likelihood of sexual problems among men but not in women. For women's problems of inability to reach orgasm, age does not seem to be systematically associated with this problem, but poor health did reach statistical significance in non-European West and East Asia. Financial problems and depression showed some positive association for this problem of inability to reach orgasm. Women who have low expectations for the future viability of their relationships are consistently more likely to report orgasmic problems. In women experiencing lubrication problems, increasing age showed curvilinear association with reporting this problem except in Southeast Asia and South America. Women aged 50-59 years compared to those 40- to 49-year olds were twice as likely to report lubrication difficulties. In East Asia the odds ratio was 2.2. Having had a hysterectomy was consistently associated with a lower likelihood of problems with lubrication. Women with depression were more likely to report lubrication problem. Women with less education were less likely to report this problem. For early ejaculation in men, education is negatively associated with this condition, with men who have a college education being twice as likely to report this problem. Experience with financial problems elevated the likelihood of reporting early ejaculation. Infrequent sex was also associated with the likelihood of this problem. For erectile difficulty aging increases reporting of this problem as well as a history of vascular condition and prostate disease. Financial problems and a history of depression elevate the likelihood of reporting erectile difficulties. Infrequent sex and men in uncommitted relationships tend to experience problems with ED more often.

As the authors pointed out, there were some limitations in the GSSAB survey including the following: differences in recruitment of samples and administration of surveys across the countries, troubles with translation of survey instruments in multiple languages to insure comparability of data, difficulties of pooling diverse populations into regional clusters which actually may represent inhomogeneous groups for statistical analysis, variation in the quality of the countryspecific survey organizations across these 29 countries, and modest response rates. Sample sizes did vary greatly with 1500 men and women in some countries, Japan being one of these, and 500 men and women in other countries such as China, Hong Kong (China), Taiwan, Indonesia, Malaysia, Phalloidins, Singapore and Thailand. In Korea, a sample size of 1200 men and women were used. Selfreports of sexual and health conditions were more likely to underestimate the true prevalence and subjects may not be aware, may not recall, or may choose not to disclose that he or she has a problem and/ or condition.

\section{DISCUSSION}

When the world literature was tabulated for presentation in the book chapter in the summary of the committee's deliberations from the Paris consensus conference, prevalence rates varied immensely because of the different ages reported, different age compositions of studies, different percentages of responders, different time periods asked about, different definitions of ED used and different strategies of collecting data (telephone interviews, mailed questionnaires, inoffice questionnaires, face-to-face interviews, single questions versus multiple versus scales). ${ }^{3}$ Similarly, the nine articles reported in this report showed the same differences for comparison. Thus, the prevalence rate of ED increases with each decade of life in all studies. Asian studies showed a $7-15 \%$ rate of ED for ages $40-49$ years and $39-49 \%$ for ages $60-70$ years. Similarly, Australian studies showed $5-6 \%$ for ages $40-49$ years and $12-13 \%$ for ages $50-59$ years. Europeans were hard to compare but roughly lower values for the total groups were reported: $3-5 \%$ for those less than 49 years of age with the widest difference of rates in those aged 50-59 years. After 60-65 years of age, ED began to increase to double digit percentages and in age 70 years and above it increased to $40-50 \%$ of the population sampled and even higher. Latin American reports varied as well and by the age of 60 years the prevalence rate of ED increased to $40-50 \%$. North American studies had similar marked increases at the age of 60 years. World studies showed a trend for higher rates for ED in the United States and in Asia compared to other regions of the world.

In the world studies, 20 studies in men were qualified as valid studies by Prins criteria for other disorders than ED. ${ }^{4}$ For sexual interest and desire disorder, prevalence rates vary from the single digit percentage to $30-40 \%$ when stratified; rates did increase with age. Orgasmic disorder and pain with sexual activity occurred in $1-5 \%$ in men. For delayed ejaculation studies show single digit to low teen rates, but premature ejaculation studies vary in prevalence rates in the mid-teens to $20-35 \%$.

Although not discussed as much in these nine papers including Asian nation data, analytical epidemiological data would be an important area for investigation in future studies for this region of the world. In the world database poor health in general was likely to concur with a low level of sexual desire/interest and ED. Increased physical activity was associated with a lower risk of ED. ED may be more prevalent in Hispanic men after controlling for other factors and prevalence for ED does increase with aging even when controlling for other diseases. New epidemiological studies show an increase in prevalence rates for ED in men who smoke as a stand alone risk. Recent literature dealing with obesity and the metabolic syndrome shows clear association with components of the syndrome-diabetes mellitus, hypertension and hypogonadism. Analysis of these data was added as a new addition to the current chapter from the Paris consensus conference. ${ }^{3}$ Hormonal and endocrine disorders are clearly associated with ED and other sexual disorders in men. Prolactin-secreting tumors are highly associated with decreased libido in men. Diabetes mellitus is highly associated with ED and decreased sexual desire; new papers highly reinforce this association. Cardiovascular disease and hypertension are the other major risk factors associated with ED; newer data link this even further. ${ }^{3}$ Other urological diseases including lower urinary tract symptoms have been associated with ED and several papers are incorporated into the consensus chapter regarding epidemiology of sexual dysfunction. ${ }^{3}$ Surgery in the pelvic region and trauma to this area damage vital neurological and vascular pathways necessary for erection and thus serve as risk factors for ED and/or ejaculatory disorders. Recent publications link sexual disorders in men with psychiatric disease and these are updated in the consensus chapter from Paris. ${ }^{3}$ Medication and recreational drugs link male sexual disorders particularly those associated with use in the psychiatric conditions. ${ }^{3}$ 
neg

Epidemiology of sexual dysfunction in Asia

RW Lewis

158

SUMMARY

There seems to be a need for country- and population-specific further descriptive and analytical epidemiological studies in all of the sexual disorders from Asia. Hopefully, this summary paper sharing these nine limited number of papers approaching and reaching evidence-based literature standards will encourage other studies from Asia that adhere to strict evidence-based criteria such as the Prink criteria. ${ }^{2}$

COMPETING FINANCIAL INTERESTS

The author declares no competing financial interests.

1 Summerskill WS. Hierarchy of evidence. In: McGovern DP, Summerskill WS, Valor RM, Levy M, editors. Key Topics in Evidence Based Medicine. Oxford: Bios Scientific Publishers; 2001. pp 15-9.

2 Pins J, Blanker MH, Bohnen AM, Thomas S, Bosch JL. Prevalence of erectile dysfunction: a systematic review of population based studies. Int J Impotence Res 2002; 14: 422-32.

3 Fugl-Meyer KS, Lewis RW, Corona G, Hayes RD, Lawman EO et al. Definitions, classification and epidemiology of sexual dysfunction. In: Sexual Medicine, Sexual Dysfunctions in Men and Women. Eds. Montorsi F, Boson R, Adaikan G, Becher E, Clayton A, Giuliano F, Khoury S, Sharlip I. Health Publication Ltd., Paris, 2010.

4 Lewis RW, Fugl-Meyer KS, Corona G, Hayes RD, Laumann EO et al. Definitions/ epidemiology/risk factors for sexual dysfunction. J Sex Med 2010; 7(4 Pt 11): 1598-607.
5 Passer LA, Rhodes T, Girman CJ, Guess HA, Chute CG et al. Sexual function of men ages 40 to 79 years: the Olmsted county study of urinary symptoms and health status among men. Jam Geriatr Soc 1995; 43: 1107-11.

6 Masumori N, Tsukamoto T, Kumamoto Y, Parser LA, Rhodes T et al. Decline of sexual function with age in Japanese men compared with American men-results of two community-based studies. Urology 1999; 54: 335-44.

7 Kongkanand A. Prevalence of erectile dysfunction in Thailand. Thai Erectile Dysfunction Epidemiological Study Group. Int J Androl 2000; 23: 77-80.

8 Lou JT, Wang Q, Ching Y, Yang X. Prevalence and risk factors of sexual dysfuncion among younger married men in a rural area in China. Urology 2005; 66: 616-22.

9 Nicolosi A, Glaser DB, Kim SC, Marumo K, Laumann EO. Sexual behavior and dysfunction and help-seeking patterns in adults aged 40-80 years in the urban population of Asian countries. BJU Int 2005; 95: 609-14.

10 Moreira ED Jr, Kim SC, Glaser D, Gingell C. Sexual activity, prevalence of sexual problems, and associated help-seeking patterns in men and women aged $40-80$ years in Korea: data from the Global Study of Sexual Attitudes and Behaviors (GSSAB). J Sex Med 2006; 3: 201-11.

11 An TY, Park JK, Lee SW, Hong JH, Park NC et al. Prevalence and risk factors for erectile dysfunction in Korean men: results of an epidemiological study. J Sex Med 2007; 4: 1269-76.

12 Nicolosi A, Mereira ED Jr, Shirai M, Bin Moho Tambi MI, Glaser DB. Epidemiology of erectile dysfunction in four countries: cross-national study of the prevalence and correlates of erectile dysfunction. Urology 2003; 61: 201-6.

13 Nicolosi A, Laumann EO, Gasser DB, Moreira ED Jr, Paik A et al. Sexual behavior and sexual dysfunction after the age 40 : the global study of sexual attitudes and behaviors. Urology 2004; 64: 991-7.

14 Lawman EO, Nicolosi A, Gasser DB, Park A, Gingell C et al. Sexual problems among women and men aged 40-80 years: prevalence and correlates identified in the Global Study of Sexual Attitudes and Behaviors. Int J Import Res 2005; 17: 39-57.

Asian Journal of Andrology 